\title{
A pain to the patient and to the doctor
}

\author{
Pedro C Brás, Sara P Dias
}

Department of Neurology, Centro Hospitalar de Lisboa Central, Lisbon, Portugal

\section{Correspondence to} Dr Pedro C Brás, Department of Neurology, Centro Hospitalar de Lisboa Central, Lisbon 1169050, Portugal; pedrocostabras@ gmail.com

Accepted 28 October 2018

\section{Check for updates}

(C) Author(s) (or their employer(s)) 2018. No commercial re-use. See rights and permissions. Published by BMJ.

To cite: Brás PC, Dias SP. Pract Neurol Epub ahead of print: [please include Day Month Year]. doi:10.1136/ practneurol-2018-002072
In the summer of 2017, I (PCB) was a fourth-year neurology resident with an interest in epilepsy working in Lisbon. I had recently started swimming, and while diving under water I began to have episodes of brief, shock-like pain inside my right jaw, each lasting less than $1 \mathrm{~s}$. The pain was located near my inferior molar teeth, although I could not pinpoint the exact tooth it came from. Later more everyday actions as toothbrushing, talking or smiling could trigger the pain, so it was impossible to avoid.

With time, these episodes increased in frequency and intensity. A month later, the same innocuous stimulus would precipitate more severe episodes of lancinating paroxysmal pain lasting up to 2 min and radiating from my right jaw to the ipsilateral cheek and forehead. They stopped abruptly and were followed by a refractory period during which pain could not be triggered. This was the worst pain I had ever experienced.

As a neurologist, I quickly suspected I had trigeminal neuralgia. As a patient, however, I convinced myself there must be another explanation. I therefore consulted a dental surgeon and underwent an orthopantomography, which was normal. For weeks, I had severe pain every time I spoke and my diet consisted solely of soft foods, which I ate only during refractory periods.

Eventually, after much insistence from my colleagues I agreed to undergo an MR scan of the brain. Routine sequences were normal but additional T2 constructive interference in steady state (CISS) images identified a neurovascular contact between my right trigeminal nerve root and the superior petrosal vein (figure 1). It is perhaps worth considering routinely performing T2 CISS sequences in patients with suspected trigeminal neuralgia to look for microvascular compression.
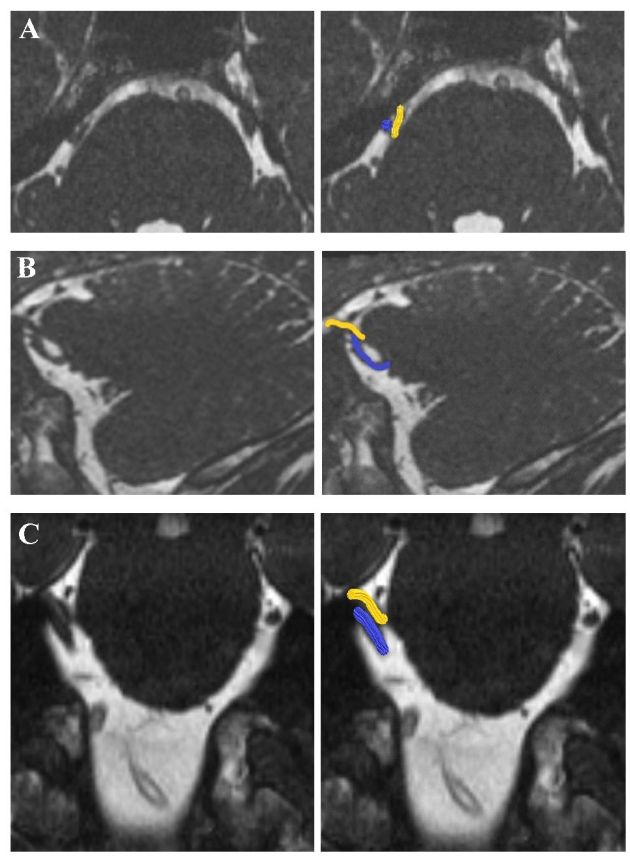

Figure 1 MR scan of the brain. (A) Axial, (B) sagittal and (C) coronal slices in T2 constructive interference in steady state sequences, showing right superior petrosal vein (marked blue) causing direct contact on the right trigeminal nerve entry zone (marked yellow). Images courtesy of Dr Jaime Pamplona, Hospital de São José, Lisbon, Portugal.

I started treatment with oxcarbazepine in increasing doses; there was only transient improvement until I reached 1800 mg daily when the attacks completely stopped. Trigeminal neuralgia usually has a good response to carbamazepine and oxcarbazepine, although with significant side effects in some. My experience indicates that it is worth sticking with effective drugs if they are tolerated. The lack of response at lower doses might have led to the introduction of another less effective drug and so missed the ultimately good therapeutic response.

Fortunately, even though I have had some adverse effects, occasional dizziness and sleepiness, I can tolerate the tablets and I have learnt to live with them: a price 
I willingly pay to control the pain, which recurs whenever I have tried to reduce the dose. One year on, I sometimes still have a strange feeling in the same area, but no pain.

I was relieved that more worrying causes of trigeminal neuralgia such as multiple sclerosis or a tumour have been excluded, but I remain concerned about my new diagnosis.

Neurovascular contact alone as the cause of trigeminal neuralgia, without more clear-cut nerve displacement, remains controversial. Such neurovascular contact may be an incidental normal anatomical variant and not necessarily the cause of the symptoms. ${ }^{1}$ In contrast, trigeminal nerve displacement by a vessel, with atrophy, is highly associated with the painful side in trigeminal neuralgia and the cause is nearly always an artery located in the root entry zone. ${ }^{1}$ Therefore, I am not sure if my neurovascular contact is causing my trigeminal neuralgia, and so I remain uncertain about my prognosis and the potential future benefits of microvascular decompression or other treatments.

Throughout this process, I had to overcome the challenges of being both a patient and a doctor. Being familiar with the available treatments and prognosis can be an advantage but also has the downside of knowing the possible complications.

Doctors are said to make the worst patients. I believe this experience has made me a better doctor. First, it helped me better understand the disease itself-I now clearly know what Armand Trousseau meant when he named it 'epileptiform neuralgia' in $1853,{ }^{2}$ since its characteristic sudden onset and offset, spreading and stereotypical episodes are indeed reminiscent of seizures. More importantly, the experience has given me a better insight into my patients' struggles. I now see the issue is not only the pain itself but also its impact on quality of life. Simple things that one performs almost unconsciously, like eating, talking, smiling or toothbrushing, become a nightmare. Even when the pain is not there, the fear of anticipation never leaves, and the condition can be a constant presence in a patient's life-if not physically, then psychologically.

Acknowledgements We thank Jaime Pamplona at the Neuroradiology Department, Centro Hospitalar Lisboa Central for kindly providing the images.

Contributors PCB developed the concept and wrote the first draft of the manuscript based on his own case. SPD developed the concept and provided significant revisions to the manuscript.

Funding The authors have not declared a specific grant for this research from any funding agency in the public, commercial or not-for-profit sectors.

Competing interests None declared.

Patient consent Not required.

Provenance and peer review Not commissioned; externally peer reviewed by Luke Bennetto, Bristol, UK.

\section{REFERENCES}

1 Maarbjerg S, Wolfram F, Gozalov A, et al. Significance of neurovascular contact in classical trigeminal neuralgia. Brain 2015;138-311-9.

2 Jannetta P. Trigeminal neuralgia. Oxford: Oxford University Press, 2010. 